Eriksen, C. W., \& Hoffman, J. E. The extent of processing of noise elements during selective encoding from visual displays. Perception \& Psychophysics, 1973, 14, 155-160.

Estes, W. K. Interactions of signal and background variables in visual processing. Perception \& Psychophysics, 1972, 12, 278-286

Estes, W. K., \& Taylor, H. A. Visual detection in relation to display size and redundancy of critical elements. Perception \& Psychophysics, 1966, 1, 9-16.

Estes, W. K., \& Wessel, D. L. Reaction time in relation to display size and correctness of response in forced-choice visual signal detection. Perception \& Psychophysics, 1966, 1, 369-373.

Kinchla, R. Detecting target elements in multi-element arrays: A confusability model. Perception \& Psychophysics, in press.

McIntyre, C., Fox, R., \& Neale, J. Effects of noise similarity and redundancy on the information processed from brief visual displays. Perception \& Psychophysics, 1970, 7, 328-332.

(Received for publication September 10, 1973.)

\title{
A note on the negative automaintenance procedure*
}

\section{ROBERT W. GRIFFIN and MICHAEL E. RASHOTTE Florida State University, Tallahassee, Fla. 32306}

Some experiments have reported that illumination of a response key prior to grain presentation to hungry pigeons establishes high levels of pecking on the lighted key despite a negative correlation between pecks and presentation of grain. Initial attempts to employ this "negative automaintenance" procedure resulted in very low levels of pecking, but pecking developed and was maintained at a high level in all pigeons when the chamber illumination, the trial length, and the intertrial interval were adjusted.

When a negative automaintenance procedure is employed with pigeons, grain presentation following brief illumination of a response key is cancelled by a single peck on the lighted key. Despite the negative correlation between keypecking and grain presentation, pigeons readily develop and maintain pecking on the lighted key in some experiments (e.g., Schwartz, 1972; Schwartz \& Williams, 1972; Williams \& Williams, 1969), but not others (Brownstein, personal communication; Granat, 1972; Hursh, Navarick, \& Fantino, in press; Passe, 1972). These findings indicate that a negative correlation between keypecks and grain presentation is not a sufficient condition for the maintenance of keypecking on the negative automaintenance procedure.

This laboratory has experienced considerable difficulty in maintaining keypecking in pigeons with the negative automaintenance procedure, and the present note reports our solution to this difficulty. A number of sources (Groves \& Brownstein, 1973; Wasserman, 1972) and personal communications ${ }^{1}$ suggested that the level of illumination in the experimental chamber and the relative durations of intertrial and trial periods might be important in obtaining high keypeck levels. Specifically, it seemed that a high level of chamber illumination in conjunction with standard key illumination, and a long intertrial interval in conjunction with a short trial duration, might yield strong keypecking. In our earlier

*This research was supported in part by Grant GB-28224 from the National Science Foundation to Florida State University (M.E.R., principal investigator). Reprints may be obtained from either author at Department of Psychology. Florida State University, Tallahassee, Fla. 32306 . unsuccessful work, the chamber was illuminated by a $25-\mathrm{W}$ bulb run at $65 \mathrm{~V}$ ac, the trial duration was $9 \mathrm{sec}$, and the intertrial interval was initially $60 \mathrm{sec}$ on the average and later was changed to $30 \mathrm{sec}$ on the average. The present paper reports high levels of keypecking in all four pigeons trained in a negative automaintenance procedure with chamber illumination and intertrial/trial durations set at "best guess" values based on available evidence. The chamber was illuminated by a $25-\mathrm{W}$ frosted bulb run at $115 \mathrm{~V}$ ac, and the intertrial and trial durations were 120 and $6 \mathrm{sec}$, respectively. Finally, in our earlier procedures, a trial was terminated by a single peck (i.e., the keylight was extinguished and food was not presented), whereas in the present work the trial duration was fixed.

\section{METHOD}

Subjects

Four experimentally naive male white Carneaux pigeons were maintained at $80 \%$ of their free-feeding weights. They were individually housed in wire mesh cages under a 24-h light-dark cycle (14 h light, $10 \mathrm{~h}$ dark). Water and grit were continuously available in the home cages.

\section{Apparatus}

Two Foringer Model 1104 test chambers $(40$ × 37.5 x $39.4 \mathrm{~cm}$ i.d.) were painted flat black and were housed in wooden boxes. A clear-plastic response key and an in-line IEE projector were mounted behind a $2.54-\mathrm{cm}$-diam hole $25.4 \mathrm{~cm}$ above the floor and $6.4 \mathrm{~cm}$ to the left of the center on one wall. Another response key on the same wall was covered. A minimum force of $28 \mathrm{~g}$ closed the switch on the response key. Grain was presented in a $5.1 \times 5.7 \mathrm{~cm}$ opening centered on the same wall, with the bottom edge of the opening $10.2 \mathrm{~cm}$ above the floor. Constant visual monitoring of each chamber was provided by television cameras mounted over an opening $(38.1 \mathrm{~cm} \mathrm{sq})$ in the ceiling of each box enclosing the test chambers. The opening was covered with chicken wire, and the area between the opening and the camera lens was enclosed by black cardboard. The chamber was illuminated by a $25-\mathrm{W}$ frosted incandescent bulb, housed in a white enclosure fronted with sandblasted Plexiglas and operated at $115 \mathrm{~V}$ ac (photometric readings obtained $0.07 \mathrm{fc}$ ). The light enclosure was mounted flush with the ceiling surface in the rear corner of the opening diagonal to the response key. White noise was delivered through a 4-in. speaker located behind the front wall. An exhaust fan provided ventilation. Total masking noise measured $78 \mathrm{~dB}$ SPL from the center of the chamber. Television monitors and electromechanical control and recording equipment were located in an adjoining room. 

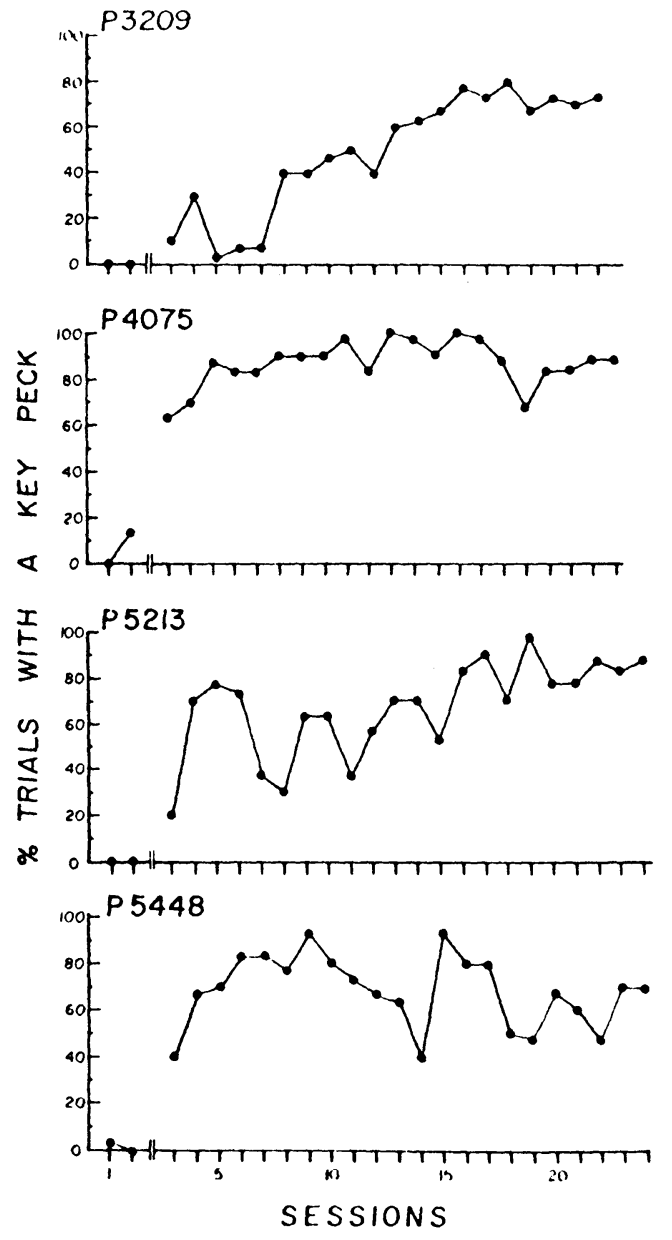

Fig. 1. Percent of trials with at least one peck in each session of the experiment.

\section{Procedure}

The experiment included three successive stages, in which sessions were run every day at approximately the same time.

During baseline, the key was illuminated white for 6 sec every $120 \mathrm{sec}$, and neither pecks on the lighted key (trial pecks) nor pecks on the dark key in the intertrial interval (ITI pecks) had scheduled consequences. Sessions ended after the 30th trial. In magazine training, each $S$ was placed in a chamber with the houselight on, the hopper raised, and approximately $5 \mathrm{~g}$ of grain in a small dish immediately in front of the hopper. The hopper was held up until a $S$ ate from it for 30 consecutive seconds, whereupon it was lowered and immediately raised again. From that point on, hopper "down time" was gradually increased, while "up time" was decreased. This session lasted approximately $30 \mathrm{~min}$. One S, P3209, required an additional day of magazine training. In negative automaintenance, 306 -sec lighted-key trials were presented at 120 -sec intervals in each session, and access to grain immediately followed any trial on which the lighted key was not pecked. If at least one trial peck occurred, grain was not presented at the end of the 6-sec keylight. The grain hopper was held up until each pigeon ate from it on the first trial of the negative automaintenance procedure. (No pigeon pecked the key on the first trial, and the hopper was programmed to be raised for $4 \mathrm{sec}$ on all remaining trials.)

The principal dependent variables calculated for each session were percent of trials with a peck, mean latency to the first trial peck, and trial pecks per minute. The latter two measures were computed on the basis of only those trials on which at least one peck occurred.

\section{RESULTS AND DISCUSSION}

Figure 1 shows the percent of trials on which at least one peck was recorded in each session.

During baseline, trial pecks occurred in P5448 on one trial in the first day and in P4075 on four trials in the second day. No ITI pecks were recorded on either day. The other two pigeons never pecked the key.

In negative automaintenance, the first trial peck occurred after 20, 3, 2, and 4 trials for P3209, P4075, P5213, and P5448, respectively. For two pigeons (P3209, P5213), the percent of trials with a peck generally increased across the first 15 sessions, while an increase occurred across the first three or four sessions for the other two pigeons. Of the pigeons which showed an increase across the initial 15 sessions, P3209 was difficult to magazine-train, had the largest number of trials prior to the first trial peck (20), and did not eat from the hopper on Trials 2-11 in the first session of negative automaintenance. This pigeon ate during every grain presentation after the 12 th trial. The other pigeon magazine-trained easily and ate on every trial.

Figure 1 shows that each pigeon eventually responded on substantially more trials each session than during baseline, and also shows no downward trend in any pigeon after 20 sessions on the procedure. The median percentages of trials with a peck in the last five sessions were 73, 83, 83, and 60 for P3209, P4075, P5213, and $\mathrm{P} 5448$, respectively. These high levels of responding often produced long runs of trials with no grain presentations. For example, P4075 received only 9 of a possible 180 grain presentations in Sessions 11-16. The maximum percentages of trials with a peck in a single session were 80, 97, 93, and 100 for P3209, P5213, $\mathrm{P} 5448$, and $\mathrm{P} 4075$, respectively.

Data from all negative automaintenance sessions were employed to compute correlation coefficients between percent of trials with at least one peck (percent) and trial pecks per minute (rate), between percent and mean latency to the first trial peck (latency), and between rate and latency. If these measures all estimate a unitary "response strength" established in the negative automaintenance procedure, percent and rate should be positively correlated whereas percent and latency, and rate and latency, should be negatively correlated. Table 1 shows that percent and rate were positively correlated at an acceptable level of statistical significance for only one pigeon, that rate and latency were negatively correlated at a significant level for two pigeons, and that the correlation between percent and latency was negative and statistically significant for two pigeons and positive and significant for one pigeon. Overall, the correlation data do not encourage the view that percent, rate, and latency provide comparable estimates of "response strength" in the present procedure. The percent measure plotted in Fig. 1 provides the most consistent estimate across animals.

In summary, even after 600 trials of negative automaintenance, pecking was maintained in all four pigeons on $60 \%-83 \%$ of trials, with no sign of a decrease. 
Thus, the present study appears to identify one experimental condition in which high levels of keypecking can be maintained despite a negative contingency between responding and food presentation. Although there was no systematic variation of experimental parameters in the present work, our overall experience with the negative automaintenance procedure is in agreement with other data suggesting the importance of chamber illumination and the ratio of trial to intertrial lengths in automaintenance procedures. Wasserman (1972) found that, in autoshaping (Brown \& Jenkins, 1968) and positive automaintenance (i.e., the trial duration is fixed and food is presented at the end of each trial irrespective of behavior), pigeons keypeck at lower levels when the chamber is dark than when it is illuminated. He interpreted this finding as support for the view that pigeons approach and contact that part of the environment which signals food presentation if the signal is highly localized. In a dark chamber, the illumination of a key provides a relatively unlocalized signal (i.e., the overall chamber illumination is increased; several surfaces show reflection), whereas in a well-illuminated chamber the lighting of the key is a highly localized event. These conditions provide a rationale for low levels of keypecking when the negative automaintenance procedure is employed under conditions designed to make the key illumination more easily "noticed" (e.g., Hursh et al, in press).

The level of keypecking in both positive and negative automaintenance procedures also appears to be influenced by the intertrial interval (Groves \& Brownstein, 1973; Jenkins, personal communication). One suggestion which has empirical support is that ratio of the trial length to intertrial length is of considerable importance if high levels of pecking are to be maintained (Groves \& Brownstein, 1973). Specifically, the strength of keypecking appears to be inversely related to this ratio: very little keypecking when the ratio is near 1.0 (key is lighted throughout most of the intertrial interval) and increased pecking as the ratio approaches 0.0 (short

Table 1

Correlation Coefficients for Three Measures of Responding in a Negative Automaintenance Procedure $\dagger$

\begin{tabular}{lccc}
\hline & $\begin{array}{c}\text { Percent } \\
\text { and } \\
\text { Rate }\end{array}$ & $\begin{array}{c}\text { Percent } \\
\text { and } \\
\text { Latency }\end{array}$ & $\begin{array}{c}\text { Rate } \\
\text { and } \\
\text { Latency }\end{array}$ \\
\hline $\begin{array}{l}\text { P3209 } \\
\text { N=20 }\end{array}$ & +0.20 & $+0.70^{*}$ & -0.15 \\
$\mathbf{P} 4075$ & & & \\
$N=21$ & +0.18 & $-0.47^{*}$ & $-0.44^{*}$ \\
P5213 & & & \\
$N=22$ & -0.09 & $-0.68^{*}$ & -0.01 \\
P5448 & & & \\
$N=22$ & $+0.45^{*}$ & -0.09 & $-0.42^{*}$ \\
\hline
\end{tabular}

tThe number of observations (N) on which the correlations are based is shown.

${ }^{*} p<.05$, one-tailed test. trials in long intertrial intervals). The precise nature of this function remains to be determined over a wide range of ratio values, and the influence of variability in the intertrial interval also needs to be established.

Some negative automaintenance procedures have arranged for the keylight to be turned off when the first trial peck is made (e.g., Williams \& Williams, 1969). Since keylight offset always immediately precedes food reinforcement (on trials without a peck), there is a possibility that keypecking is maintained in this variety of negative automaintenance by the conditioned reinforcing properties of light offset (e.g., Hursh et al, in press; Schwartz, 1972). The high level of keypecking maintained in both the present experiment and in the experiments in which keypecking had no effect on key illumination (Schwartz, 1972; Wasserman, 1972, Experiment 7) indicates that this possibility should be rejected.

And finally, a concept of "species specificity" was invoked to explain how levels of responding in the monkey (Gamzu \& Schwam, 1973) and the crow (Powell, 1973) during a negative automaintenance procedure. Since chamber illumination and trial/intertrial durations are important variables for maintaining keypecking in pigeons under a negative automaintenance procedure, such a conclusion regarding the monkey and the crow may be premature.

\section{REFERENCES}

Brown, P. L., \& Jenkins, H. M. Autoshaping of the pigeons' key peck. Journal of the Experimental Analysis of Behavior, 1968, 11, 1-8.

Gamzu, E., \& Schwam, E. The generality of autoshaping: The squirrel monkey doesn't peck. Paper presented at the meeting of the Eastern Psychological Association, Washington, D. C. 1973.

Granat, $M$. The role of conditioned reinforcement in automaintenance. Unpublished master's thesis, Western Michigan University, 1972

Groves, C. C., \& Brownstein, A. J. Effects of trial and cycle durations on automaintenance. Paper presented at the meeting of the Southeastern Psychological Association, New Orleans, 1973.

Hursh, S. R., Navarick, D. J., \& Fantino, E. "Automaintenance": The role of reinforcement. Journal of the Experimental Analysis of Behavior, in press.

Passe, D. Adventitious reinforcement and conditioned reinforcement in automaintenance. Unpublished master's thesis, Western Michigan University, 1972.

Powell, R. E. Failure to obtain auto-shaping and negative automaintenance in the common crow. Paper presented at the meeting of the Southeastern Psychological Association, New Orleans, 1973.

Schwartz, B. The role of positive conditioned reinforcement in the maintenance of key pecking which prevents delivery of primary reinforcement. Psychonomic Science, 1972, 28 , 277-278.

Schwartz, B., \& Williams, D. R. The role of the response-reinforcer contingency in negative automaintenance. Journal of the Experimental Analysis of Behavior, 1972, 17, 351-357.

Wasserman, E. A. Auto-shaping: The selection and direction of behavior by predictive stimuli. Unpublished doctoral dissertation, Indiana University, 1972.

Williams, D. R \& \& Williams, H. Auto-maintenance in the pigeon: Sustained pecking despite contingent non-reinforcement. Journal of the Experimental Analysis of Behavior, 1969, 12 511-520.

\section{NOTE}

1. Particularly helpful were communications with Herbert Jenkins, David Williams, Aaron Brownstein, and Lee Groves.

(Received for publication August 10, 1973.) 